\title{
EDITORIAL
}

\section{In This Issue: Multilevel Effects}

\author{
Kurt C. Stange, $M D, P b D$, Editor \\ Ann Fam Med 2015;13:510-511. doi: 10.1370/afm.1876.
}

$\mathrm{T}$ his issue is about the multilevel, multidimensional, multimorbid, multifactorial, multidisciplinary factors that interact in sometimes complex ways to enhance or diminish health. These articles serve as antidotes to the simplistic idea that understanding is about a single factor, or that improvement is about a single decontextualized intervention.

A multifaceted intervention is shown by Clyne et al to be successful in reducing potentially inappropriate prescribing among older people. ${ }^{1}$

Quality of care for diabetes is complexly associated with practice-level rates of other chronic conditions, particularly conditions that have similar pathophysiological risk profiles and therefore similar management plans. ${ }^{2}$

Yaeger et al show both the potential of linking electronic health records with community data and the challenge of finding higher level community effects, in their study that identifies both established and new factors associated with appropriate management of upper respiratory infections. ${ }^{3}$

Obstructive sleep apnea already is known to be worthy of diagnosis because of the effect of treatment on the quality of life of many patients. However, a special report by McKay from the National Transportation Safety Board shows that when the sufferer has a job that affects others, an individual's undiagnosed obstructive sleep apnea can have a tragic effect on the lives of others. ${ }^{4}$

Care managers are found to provide the essential primary care attributes of accessibility, coordination of care, and relationship for people with chronic disease, frequent health care use, and for their caregivers, in a study by Hudon and colleagues. ${ }^{5}$

Two excellent systematic reviews, for which the Annals editorial fellow Aaron Orkin very capably served as editor, identify the effects of often multifaceted interventions. Vedel and colleagues find that high intensity or moderate intensity transitional care interventions of at least 6 months duration are most effective for avoiding hospital readmission and emergency department visits for patients with congestive heart failure seen in primary care. ${ }^{6}$ A meta-analysis of the efficacy of mindfulness-based interventions in primary care adds value by providing an assessment of the overall effectiveness of interventions, and by identifying high heterogeneity around improving mental health and low heterogeneity in improving quality of life. The review also highlights innovative approaches for implementing mindfulness-based interventions. ${ }^{7}$

The conjoint video-stimulated perspectives of patients and general practitioners around visits for osteoarthritis provides a number of insights that can be used by clinicians to improve our care. It provides particular insight into use of terminology to describe osteoarthritis, and too-frequent normalization of symptoms and provision of unsought reassurance in visits that often involve multimorbidity and multiple, implicit patient agendas. ${ }^{8}$

Mixed qualitative and quantitative studies often require readers to wade through a lot of words to get a payoff of rich insights from the cross-talk between numbers and narrative. A helpful methodology study brings to light the use of visual joint displays that creatively convey summary statistics and stories, sometimes joined by theory or recommendations. These pictures may be worth a thousand words in communicating effectively the results and implications of complex studies. ${ }^{9}$

An essay by Kannai about her fellow physician, friend, and mentor conveys many lessons. For me, it is a reminder that even for stoic physicians devoting their lives to others, selectively sharing, rather than hiding vulnerability may be a gift. $^{10}$

Finally, the editorial team wishes to mark two transitions.

We are grateful to Paul A. Nutting, MD, MSPH for his many contributions to improving population health and primary health care, and particularly for his long service as Annals Associate Editor and then as Consulting Editor. Paul brought a wealth of wisdom and experience to his work with us, and he made those of us who interacted with him better. Thank you for the privilege of working with you, Paul. Currently Paul is making tangible the truism that a picture is worth a thousand words. You can see some of his recent work at: http://paulnutting.com/. 
We are delighted to announce that Timothy Daaleman, DO, MPH has joined the Annals team as Associate Editor. Tim is Professor and Vice Chair of Family Medicine at the University of North Carolina at Chapel Hill. He has been an outstanding reviewer for Annals for many years, and brings to this new role diverse and relevant experience as a clinician, researcher, and leader.

We welcome your reflections at http://www. Ann FamMed.org.

\section{References}

1. Clyne B, Smith SM, Hughes CM, et al. Effectiveness of a multifaceted intervention for potentially inappropriate prescribing in older patients in primary care: a cluster-randomized controlled trial (OPTISCRIPT Study). Ann Fam Med. 2015;13(6):545-553.

2. Ricci-Cabello I, Stevens S, Kontopantelis E, et al. Impact of the prevalence of concordant and discordant conditions on the quality of diabetes care in family practices in England. Ann Fam Med. 2015;13(6):514-522

3. Yaeger JP, Temte JL, Hanrahan L, Martinez-Donate A. Roles of clinician, patient, and community characteristics in the management of pediatric upper respiratory tract infections. Ann Fam Med. 2015;13(6):529-536.
4. McKay M. Fatal consequences: obstructive sleep apnea in a train engineer. Ann Fam Med. 2015;13(6):583-586.

5. Hudon C, Chouinard M, Diadiou F, Lambert M, Bouliane D. Case management in primary care for frequent users of health care services with chronic diseases: a qualitative study of patient and family experience. Ann Fam Med. 2015;13(6):523-528.

6. Vedel I, Khanassov V. Transitional care for patients with congestive heart failure: a systematic review and meta-analysis. Ann Fam Med. 2015;13(6):562-571

7. Demarzo MM, Montero-Marin J, Cuijpers $P$, et al. The efficacy of mindfulness-based interventions in primary care: a meta-analytic review. Ann Fam Med. 2015;13(6):573-582.

8. Paskins Z, Sanders T, Croft P, Hassell A. The identity crisis of osteoarthritis in general practice: a qualitative study using videostimulated recall. Ann Fam Med. 2015;13(6):537-544.

9. Guetterman TC, Fetters MD, Creswell JW. Integrating quantitative and qualitative results in health science mixed methods research through joint displays. Ann Fam Med. 2015;13(6):554-561.

10. Kannai R. The untaught lesson. Ann Fam Med. 2015;13(6):587-588.

\section{CORRECTION}

Ann Fam Med 2015;13:511. doi: 10.1370/afm.1880

Wallis KA. Learning from no-fault treatment injury claims to improve the safety of older patients. Ann Fam Med. 2015;13(5):472-474.

A careful Annals reader has pointed out an error in Table 2. Under the heading for All Medication Injuries, Total $\mathrm{N}=1,423$, in the row containing data for Aspirin, the total should be 7, not 77 and the percentage 0 , not 5 . The author regrets the error. 